\title{
Cross-cultural adaptation of the Type D Personality Scale for use with patients diagnosed with Ischemic Heart Disease in Sri Lanka
}

\author{
Chandima Kumara Walpita Gamage ${ }^{1}$, Piyanjali de Zoysa ${ }^{2}$, Aindralal Balasuriya ${ }^{3}$, Neil Fernando ${ }^{3}$, \\ B Deepal W Jayamanne ${ }^{4}$
}

(Index words: Ischemic Heart Disease, Type D Personality, DS-14)

\begin{abstract}
Introduction Ischemic Heart Disease (IHD), a major cardiovascular disease globally, has become the primary cause of death in Sri Lanka. Negative affectivity (NA) and social inhibition (SI) are two personality traits which increase the risk of IHD. The Type D Scale (DS-14) evaluates a person's general level of distress on NA and SI. However, DS-14 has not been translated and validated into Sinhala in Sri Lanka.

Objectives The study aimed to cross-culturally adapt and validate the DS-14 for use with Sinhala speaking patients diagnosed with IHD.

Methods Translation, back translation and pre-test were conducted before two-rounds of a Delphi process which assessed content and consensual validity of the instrument. The validated questionnaires were administered to 140 patients diagnosed with IHD at a Base Hospital. Factor structure was confirmed through Exploratory Factor Analysis (EFA) and Confirmatory Factor Analysis (CFA) and reliability, by internal consistency with Cronbach's alpha.
\end{abstract}

Results The questionnaire was administered among 140 participants ( 85 females), aged $18-60$ years. The DS-14 Sinhala version showed good content and consensual validity. Factor analysis proved two factors compatible with the original instrument, which explained the variance of $62.9 \%$. CFA confirmed the two-factor model. The reliability analysis indicated Cronbach's alpha for NA and SI as 0.93 and 0.88 , respectively.

Conclusion The cross-culturally adapted DS-14 Sinhala version indicated the same psychometric properties as the original instrument, in the local context with IHD patients. It can be confidently applied in the investigation of Type D personality in IHD prevention and treatment, as well as in research.

Ceylon Medical Journal 2021; 66: 8-15

DOI: http://doi.org/10.4038/cmj.v66i1.9350

\section{Introduction}

Ischemic heart disease (IHD) is considered the foremost cause of death [1], and disability around the world and its prevalence are approximately one in every six deaths in Western countries [2]. Although the mortality of IHD has declined gradually over the last decades in Western countries, it is still responsible for about onethird of all deaths in individuals older than 35 years of age [1]. Further, a study conducted among individuals over 18 years revealed that the IHD prevalence was 6.1, 6.4, 5.3 and 3.7\% in Caucasian, African, Latino and Asian populations, respectively [3]. Moreover, it is the prevalence increases with age, and males are at a higher risk [4]. A study has indicated that IHD deaths in Southeast Asia have amplified from 5.73 to 8.14 million from 1990 to 2013 [5]. Ischemic Heart Disease has been identified as the foremost cause of morbidity and mortality in Sri Lanka [6] where risk factors are more significant in urban areas, higher socioeconomic classes and among younger people $[7,8]$.

Psychological distress is closely related to the advancement of IHD and directly associated with the medical consequences of IHD $[9,10]$. Type D (distressed) personality is an emerging risk factor in patients with cardiovascular diseases (CVDs) and closely connected with poor prognosis, reduced health status, and mental health issues such as depression, anxiety and Post Traumatic Stress Disorder [12-14]. DS-14 (14) is an instrument which is used to evaluate a personality type commonly associated with IHD, and it was developed from the 16-item, DS-16 [15] scale. The impact of Type D personality on the prognosis of CVDs has been widely discussed with the use of both instruments $[16,17]$. Type $\mathrm{D}$ personality is the person's consistent inclination to experience negative affectivity (NA) and social inhibition (SI) [18]. While NA signifies the inclination to experience

${ }^{1}$ Faculty of Allied Health Sciences, Kotelawala Defence University, Sri Lanka, ${ }^{2}$ Faculty of Medicine, University of Colombo, Sri Lanka, ${ }^{3}$ Faculty of Medicine, Kotelawala Defence University, Sri Lanka, ${ }^{4}$ Faculty of Medicine, University of Kelaniya, Sri Lanka.

Correspondence: CK, e-mail: <ckumara@kdu.ac.Ik>. Received 18 August 2020 and revised version 16 November 2020 accepted 20 March 2021.

This is an open-access article distributed under the terms of the Creative Commons Attribution License, which permits unrestricted use, distribution, and reproduction in any medium, provided the original author and source are credited. 
negative emotions (i.e. depression, anger, anxiety), SI signifies restraining from disclosing feelings and opinions in social interactions to avoid others' disapproval [18].

The DS-14, which describes the Type D personality shows two factorial NA and SI dimensions [18]. The Type D personality and the factorial structure of DS-14 have been widely explored and validated in many countries [1925]. Further, the internal consistencies of these various validated versions are acceptable [i.e.; United Kingdom and Ireland $(\alpha \mathrm{NA}=0.85 ; \alpha \mathrm{SI}=0.82)$ [25]; Denmark $(\alpha \mathrm{NA}$ $=0.83 ; \alpha \mathrm{SI}=0.76)$ [22]; Turkey $(\alpha \mathrm{NA}=0.82 ; \alpha \mathrm{SI}=0.81)$ [26]. Since only a few research studies have been carried out on Type D personality in non-western contexts, the information available on the applicability of Type D typology in these other cultures is low [28-31], for which an instrument that assesses Type $\mathrm{D}$ personality is required.

Although several studies have been conducted in Sri Lanka on diverse aspects of IHD, no instrument has been found in Sinhalese with proven reliability and validity which assesses Type D personality in IHD patients. The majority ( $>75 \%$ ) of Sri Lankans speak the Sinhala language as the mother tongue, and having an instrument in the Sinhala language to evaluate type $\mathrm{D}$ personality will be valuable in the treatment and prevention of IHD which has become a crisis in the country. Therefore, the present study was carried out to cross-culturally adapt and evaluate the validity and reliability of the DS-14 for use in patients diagnosed with IHD in Sri Lanka.

\section{Methods}

The DS14 is consisted of NA and SI where the subjects are rated on their personality on a 5-point Likert scale ranging from $0=$ false to $4=$ true. The NA and SI scales can be scored as continuous variables (ranging from 0 -28) to assess these personality traits in their own right. A cutoff of 10 on both scales is used to classify subjects as Type D (i.e., NA $\geq 10$ and $\mathrm{SI} \geq 10$ ).

\section{Study population}

Participants were chosen using the systematic sampling method, from patients who are diagnosed with IHD attending medical clinics at a Base Hospital in the Southern Province of Sri Lanka. Patients between 18-60 years and diagnosed with IHD within the last three months of the data collection were selected for the study. The selection of IHD patients were done by going through their clinic records and by further confirming the diagnosis of IHD with the physicians working in the medical clinics at the Base Hospital. Among them, patients of various ethnic groups and competent in the Sinhala language were selected. Patients who had significant health problems, physical disabilities, previously diagnosed with significant health problems (data were gathered through previous clinic reports), critically ill and pregnant women were omitted. The DS-14 is consisted of 14 items and the participants per item were kept at a ratio of $5: 1$ as per the literature [31]. Accordingly, the calculated total sample size of the validation study was 140 by allocating equal subsamples for CFA $(n=70)$ and EFA $(n=70)$.

\section{Translation and pre-test}

Initially, the instrument was translated and then it was back-translated, the translated version back into English by two subject specialized professional translators. Afterwards, to determine the conceptual equivalency of the translated and back-translated versions, they were scrutinised by a bilingual professional in the field of behavioural sciences, and the corrections were made accordingly.

A structured interview with four patients diagnosed with IHD was carried out as the pre-test of the DS-14 Sinhala version. Minor revisions were made according to the comments made by these patients on aspects such as the ease of comprehending the instrument, difficulty level when responding, and the length of the DS-14 instrument's items.

\section{Content and consensual validity}

The content and consensual validity were determined by an expert panel of two psychiatrists and four clinical psychologists through a Delphi process. In terms of consensual validity, the panel of experts rated each item, on a scale of 0 (total disagreement) to 9 (full agreement): (i) if an item's conceptual meaning was maintained after it was translated to Sinhala; (ii) if the items were suitable to be used with patients diagnosed with IHD, and (iii) if the instrument items were culturally relevant to Sri Lanka. Concerning content validity, the panel of experts again rated the instrument from 0 to 9: (i) if each item was a suitable indicator of its scale/sub-scale, and (ii) if the combination of items in the scale/sub-scale was adequate to measure the concept assessed by the scale/sub-scale. The ratings received from stage one was summarised and presented for a second round of the Delphi Process. The repeat ratings were evaluated for their degree of consensus.

\section{Ethical considerations}

Initially, the permission was obtained from the original author to translate, cross-culturally adapt and validate the DS-14 into the Sinhala language. Ethics approval was obtained from the Ethics Review Committee, Faculty of Medicine, University of Colombo, Sri Lanka (EC-18-011) and institutional permission was obtained from the Medical Superintendent of the Base Hospital in which the patient data was collected. Informed written consent was obtained from all the study participants. 


\section{Statistical analysis}

Exploratory Factor Analysis (EFA) and Confirmatory Factor Analysis (CFA) were performed by the R (3.6) and R Studio (1.2) statistical software to evaluate the invariance of the instrument, and model-data fit. The data were divided randomly into two equal subsamples; one subsample was used to analyse EFA $(n=70)$, and the other was used to do CFA $(n=70)$ to confirm the factorial structure of the original study.

To evaluate the sample adequacy subsample for the exploratory factor analysis, the Kaiser-Meyer-Olkin (KMO) measure and Bartlett test of sphericity were performed, and KMO values of $\geq 0.70$ were considered average [32]. A scree plot was shown to determine the number of components to extract. EFA by principal components was performed with Varimax rotation. Reliability was verified with internal consistency, using Cronbach's alpha, and coefficients of $\geq 0.70$ were considered to possess a satisfactory internal consistency [33]. In CFA, following values were calculated and compared: the comparative fit index (CFI), the Tucker-Lewis index (TLI), the incremental fit index (IFI), the root-mean-square error of approximation (RMSEA), the ratio of chi-squared test $\chi^{2}$ to the degree of freedom $\left(\chi^{2} / \mathrm{df}\right)$. The two-factor model of the original study was tested. The model was considered as consistent with the experimental data at the values of CFI [34], TLI [35] and IFI $\geq 0.90$, RMSEA [36] less than 0.08 and $\chi^{2} / \mathrm{df}$ less than five.

\section{Results}

\section{Sample characteristics}

The study sample population consisted of 140 which represented 39.3\% ( $n=55)$ males and $60.7 \%(n=85)$ females. The average age was 53.87 years $(S D \pm 4.10)$ and the age range found was 34-59. All the participants were Sinhalese $(100 \% ; n=140)$ and the majority $(43.6 \% ; n=61)$ had studied up to GCE (Ordinary Level) Examination (Table 1).

\section{Delphi process}

The following principles were used in the Delphi process to select the items in DS-14 Sinhala version; (i) if $70 \%$ or more of the re-ratings were in category $0-3$, that item/sub-scale was omitted or reworded to make it acceptable. If reworded, the Delphi Process was repeated for that item/sub-scale, and (ii) if $70 \%$ or more of the reratings were in categories 4-6 and 7-9 (summatively), that item/subscale was retained. None of the items was removed from the original instrument. Some items were reworded according to suggestions made at stage one, by the experts, to retain the conceptual meaning when translated to Sinhala.

\section{Factor structure}

\section{Exploratory factor analysis (EFA)}

The KMO-index (0.83) and Bartlett's test of sphericity $\left(\chi^{2}(91)=559.68, \mathrm{p}<0.05\right)$ showed appropriate sample adequacy on the data to carry out the factor analysis. EFA (Principal components, Varimax rotation) of the DS-14 items showed two components (Eigenvalue $>1$ ) explaining $62.90 \%$ of the variance $(34.69 \%$ of the first factor and $28.21 \%$ of the second factor (Table 2). The scree plot showed a significant break after the $2^{\text {nd }}$ component. Using Cattell's scree test, and it was confirmed to retain two components (Figure 1).

Table 1. Sample characteristics

\begin{tabular}{|c|c|c|c|}
\hline \multicolumn{2}{|c|}{ Demographic characteristics } & \multicolumn{2}{|l|}{ Sample $(n=140)$} \\
\hline & & Frequency & Percentage (\%) \\
\hline \multirow[t]{3}{*}{ Age } & & Mean $=53.87$ & \\
\hline & & $\mathrm{SD} \pm 4.096$ & \\
\hline & & Range $=34-59$ years & \\
\hline \multirow[t]{2}{*}{ Gender } & Male & 55 & 39.3 \\
\hline & Female & 85 & 60.7 \\
\hline Race & Sinhala & 140 & 100 \\
\hline \multirow[t]{4}{*}{ Level of education } & No schooling & 20 & 14.3 \\
\hline & Primary & 55 & 39.3 \\
\hline & Ordinary Level & 61 & 43.6 \\
\hline & Advanced Level & 04 & 2.9 \\
\hline
\end{tabular}




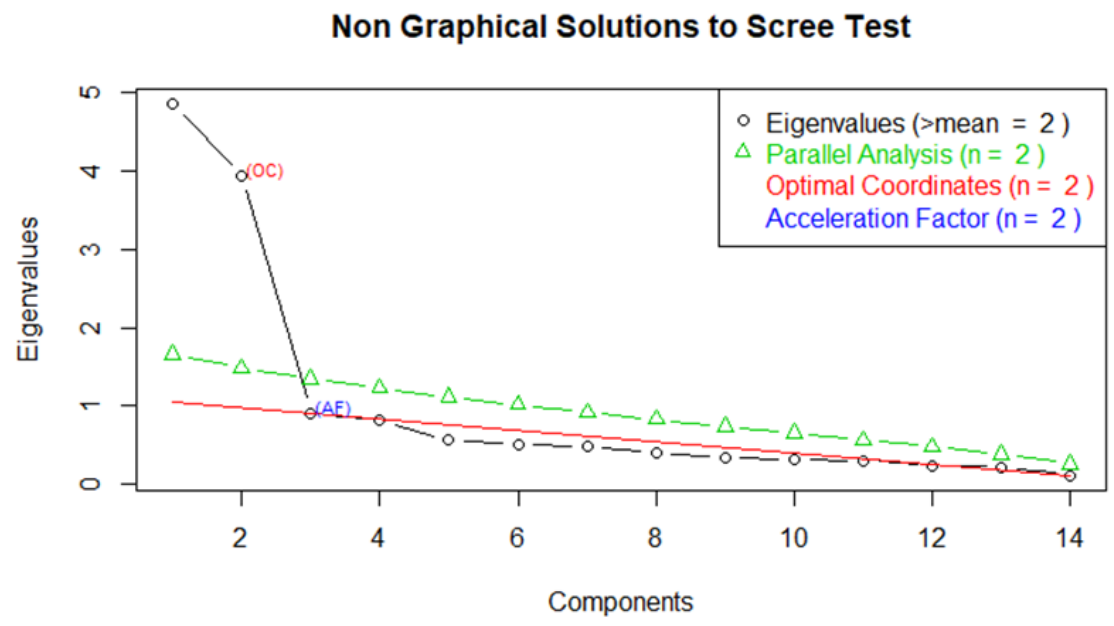

Figure 1. Scree plot showing the eigenvalues of the factors representing the items from the DS-14 for IHD patients.

Table 2. Factor structures and loadings of 14 items in DS-14 (*values above 0.5)

\begin{tabular}{|c|c|c|c|}
\hline \multirow[t]{2}{*}{ Items of the DS14 } & \multicolumn{2}{|c|}{ FA-Total sample } & \multirow{2}{*}{$\begin{array}{l}\text { Internal } \\
\text { consistency }\end{array}$} \\
\hline & Factor I & Factor II & \\
\hline \multicolumn{4}{|l|}{ Negative affectivity } \\
\hline 4. I often feel unhappy & $0.71 *$ & 0.06 & 0.81 \\
\hline 7. I take a gloomy view of things & $0.79 *$ & 0.14 & 0.82 \\
\hline 13. I am often down in the dumps & $0.91 *$ & -0.02 & 0.91 \\
\hline 2. I often make a fuss about unimportant things & $0.75^{*}$ & 0.01 & 0.82 \\
\hline 12. I often find myself worrying about something & $0.88^{*}$ & 0.02 & 0.92 \\
\hline 5. I am often irritated & $0.55^{*}$ & 0.16 & 0.73 \\
\hline 9. I am often in a bad mood & $0.79 *$ & -0.08 & 0.82 \\
\hline eigenvalue $\mathrm{I}=4.25$ & & & $\alpha=0.93$ \\
\hline \multicolumn{4}{|l|}{ Social inhibition } \\
\hline 6. I often feel inhibited in social interactions & 0.04 & $0.83^{*}$ & 0.84 \\
\hline 8. I find it hard to start a conversation & -0.06 & $0.74 *$ & 0.80 \\
\hline 14. When socialising, I do not find the right things & & & \\
\hline to talk about & 0.01 & $0.52 *$ & 0.64 \\
\hline 10. I am a closed kind of person & -0.02 & $0.73 *$ & 0.78 \\
\hline 11. I would rather keep other people at a distance & 0.10 & $0.75^{*}$ & 0.75 \\
\hline 1. I make contact easily when I meet people & 0.06 & $0.74 *$ & 0.78 \\
\hline 3. I often talk to strangers & 0.15 & $0.75^{*}$ & 0.79 \\
\hline eigenvalue II = 3.76 & & & $\alpha=0.88$ \\
\hline
\end{tabular}




\section{Confirmatory factor analysis (CFA)}

CFA was performed to test the predicted two-factor structure of the DS14 directly. The second sample ( $n=70)$ was used to check the factorial structure of the original study. A CFA of the two-factor structure of the DS-14 Sinhala version indicated a good model fit. The two-factor model gave a chi-squared value of $559.68(\mathrm{df}=91)(\mathrm{p}<0.001)$, and for the 2-factor solution we found, CFI=0.919, TLI=0.903 and RMSEA=0.104 (90\% CI 0.074-0.133), confirming full conformity of the theoretical two-factor model with the obtained data.

\section{Reliability analysis}

Cronbach's alpha values on the subscale of NA and SI were 0.93 and 0.88 , respectively. Mean inter-item total correlations were identified as 0.645 for the NA and 0.522 for SI items. The values for "alpha if item deleted" in both subscales NA and SI were lower than corresponding subscale values in the alpha of 0.001 . Therefore, the Cronbach's alpha coefficient proved an acceptable internal consistency for the two subscales of the DS-14 Sinhala version.

Table 3. Internal consistencies for each subscale in the current study, original study, and other studies

\begin{tabular}{lcc}
\hline Study & Negative affectivity & Social inhibition \\
Original study & 0.89 & 0.82 \\
Sinhalese version (Current study) & 0.93 & 0.88 \\
Chinese version & 0.90 & 0.85 \\
Danish version & 0.87 & 0.83 \\
Norwegian study & 0.87 & 0.86 \\
Persian version & 0.84 & 0.88 \\
French version & 0.88 & 0.83 \\
\hline
\end{tabular}

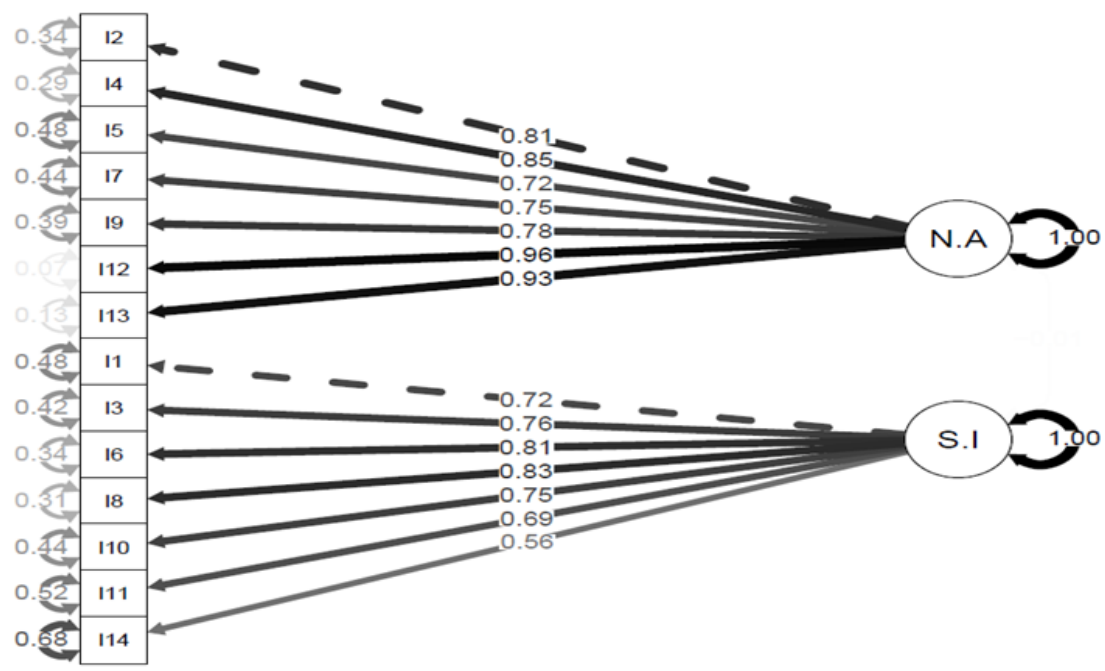

Figure 2. Confirmatory factor analysis path diagram for the DS-14. NA (negative affectivity), SI (social inhibition). 


\section{Discussion}

Negative affectivity (NA) and social inhibition (SI) are two traits which increase the risk of $\operatorname{IHD}(11)$ and impacts its treatment and prevention. The DS-14 is a widely used instrument, with excellent psychometric properties, which evaluates an individual's general level of distress, based on NA and SI. The present study aimed to translate, cross-culturally adapt, and assess the psychometric properties of the Sinhala version of DS-14, as an assessment tool to detect type D personality among the Sinhala speaking community.

Forward translation, back translation, bilingual scrutinization, and pre-tests were undertaken to obtain acceptable content and consensual validity of the instrument. Two rounds of the Delphi process tested content and consensual validity. The Delphi panel consisted of experts in mental health - two psychiatrists and four clinical psychologists. None of the items was removed from the original instrument, and rewording of some items was done according to suggestions made by some experts, such that the conceptual meaning was retained when translated to Sinhala.

EFA was performed to find out the probable underlying factors, and CFA was utilized to confirm the factor structure. Exploration of factor structure was led with the first subsample data, and verification of factor, with other subsample data, considering the recommendations $[37,38]$. Factor analyses of the DS-14 in several different languages had identified NA and SI items loading on the two factors $[22,24,30,39,40]$. Considering the CFA data, an acceptable model fit with construct validity was detected, and the values of the fit guides for the two-factor model were acceptable and closer to the desired level. Therefore, the original two-factor model best fitted and clarified the items of the DS-14 Sinhala version in the tested sample.

Reliability analysis was performed through evaluating the internal consistency using Cronbach's alpha. Cronbach's alpha coefficients were calculated for each subscale were $\mathrm{NI}=0.93$ and $\mathrm{SI}=0.88$; all of which lie above the commonly accepted thresholds for internal consistency. Results are equivalent to those of the original study and other language versions $[22,24,30,39,40]$ as illustrated in table 03.

\section{Conclusion}

The validated DS-14 Sinhala version has indicated acceptable psychometric properties, in par with the original instrument. It can confidently be applied in research, investigation of Type D personality and IHD preventive programmes.

\section{Data availability}

The data used to support the findings of this study are available with the corresponding author upon request.

\section{Conflicts of interest}

All authors declare that they have no conflicts of interest.

\section{Acknowledgements}

The authors acknowledge Johan Denollet, the developer of DS-14, for his assistance, which made it possible for this study to be carried out. We also appreciate the translators and experts who have attended in Delphi process, which provided us with valuable comments and suggestions. Special thanks are due to all participating patients at Base Hospital.

\section{References}

1. Roger VL. Epidemiology of myocardial infarction. Med Clin North Am. 2007; 91(4): 537-52; ix.

2. Roger VL, Go AS, Lloyd-Jones DM, Benjamin EJ, Berry JD, Borden WB, et al. Heart disease and stroke statistics 2012 update: a report from the American Heart Association. Circulation 2012; 125(1): e2-220.

3. Global, regional, and national age-sex specific all-cause and cause-specific mortality for 240 causes of death, 19902013: a systematic analysis for the Global Burden of Disease Study 2013. Lancet [Internet]. 2015 Jan 10 [cited 2019 Dec 3]; 385(9963): 117-71. Available from: https:// www.ncbi.nlm.nih.gov/pmc/articles/PMC4340604/

4. Mozaffarian D, Benjamin EJ, Go AS, Arnett DK, Blaha MJ, Cushman M, et al. Heart disease and stroke statistics - 2015 update: a report from the American Heart Association. Circulation 2015; 131(4): e29-322.

5. Roth GA, Forouzanfar MH, Moran AE, Barber R, Nguyen G, Feigin VL, et al. Demographic and epidemiologic drivers of global cardiovascular mortality. $N$ Engl J Med. 2015; 372(14): 1333-41.

6. Mendis S, Ekanayake EMTKB. Prevalence of coronary heart disease and cardiovascular risk factors in middle aged males in a defined population in central Sri Lanka. Int $J$ Cardiol [Internet]. 1994 Sep [cited 2019 Dec 11]; 46(2): 135-42. Available from: https://linkinghub.elsevier.com/ retrieve/pii/0167527394900345

7. Wijewardene K, Mohideen MR, Mendis S, Fernando DS, Kulathilaka T, Weerasekara D, et al. Prevalence of hypertension, diabetes and obesity: baseline findings of a population-based survey in four provinces in Sri Lanka. Ceylon Med J. 2005; 50(2): 62-70.

8. Katulanda P, Wickramasinghe K, Mahesh JG, Rathnapala A, Constantine GR, Sheriff R, et al. Prevalence and correlates of tobacco smoking in Sri Lanka. Asia Pac J Public Health 2011; 23(6): 861-9.

9. Kent LK, Shapiro PA. Depression and related psychological factors in heart disease. Harv Rev Psychiatry 2009; 17(6): 377-88. 
10. Rozanski A, Blumenthal JA, Davidson KW, Saab PG, Kubzansky L. The epidemiology, pathophysiology, and management of psychosocial risk factors in cardiac practice: the emerging field of behavioral cardiology. J Am Coll Cardiol. 2005; 45(5): 637-51.

11. Denollet J, Schiffer AA, Spek V. A general propensity to psychological distress affects cardiovascular outcomes: evidence from research on the type D (distressed) personality profile. Circ Cardiovasc Qual Outcomes 2010; 3(5): 546-57.

12. Dekker J. Theories in behavioral medicine. Int J Behav Med. 2008; 15(1): 1-3

13. Mommersteeg PMC, Denollet J, Kavelaars A, Geuze E, Vermetten E, Heijnen CJ. Type D personality, temperament, and mental health in military personnel awaiting deployment. Int J Behav Med. 2011; 18(2): 131-8.

14. Denollet J. DS14: standard assessment of negative affectivity, social inhibition, and Type D personality. Psychosom Med. 2005; 67(1): 89-97.

15. Denollet J. Personality and coronary heart disease: the typeD scale-16 (DS16). Ann Behav Med Publ Soc Behav Med. 1998; 20(3): 209-15.

16. Pedersen S, Denollet J. Is Type D Personality Here to Stay? Emerging Evidence Across Cardiovascular Disease Patient Groups. Curr Cardiol Rev [Internet]. 2006 Aug 1 [cited 2019 Dec 18]; 2(3): 205-13. Available from: http:// www.eurekaselect.com/openurl/content. php?genre=article \&issn=1573-403X \&volume=2\&issue=3\&spage=205

17. Orth-Gomér K, Albus C, Bagés N, DeBacker G, Deter H-C, Herrmann-Lingen C, et al. Psychosocial considerations in the European guidelines for prevention of cardiovascular diseases in clinical practice: Third Joint Task Force. Int $J$ Behav Med. 2005; 12(3): 132-41.

18. Denollet J. DS14: Standard Assessment of Negative Affectivity, Social Inhibition, and Type D Personality: Psychosom Med [Internet]. 2005 Jan [cited 2019 Dec 11]; 67(1): 89-97. Available from: https://insights.ovid.com/ crossref?an=00006842-200501000-00013

19. Spindler H, Kruse C, Zwisler A-D, Pedersen SS. Increased anxiety and depression in Danish cardiac patients with a type D personality: cross-validation of the Type D Scale (DS14). Int J Behav Med. 2009; 16(2): 98-107.

20. Williams L, O’Connor RC, Howard S, Hughes BM, Johnston DW, Hay JL, et al. Type-D personality mechanisms of effect: the role of health-related behavior and social support. J Psychosom Res. 2008; 64(1): 63-9.

21. Grande G, Jordan J, Kümmel M, Struwe C, Schubmann R, Schulze F, et al. [Evaluation of the German Type D Scale (DS14) and prevalence of the Type D personality pattern in cardiological and psychosomatic patients and healthy subjects]. Psychother Psychosom Med Psychol. 2004; 54(11): 413-22.
22. Pedersen SS, Denollet J. Validity of the Type D personality construct in Danish post-MI patients and healthy controls. J Psychosom Res. 2004; 57(3):265-72.

23. Gremigni P, Sommaruga M. Personalita di Tipo D, un costrutto rilevante in cardiologia. Studio preliminare di validazione del questionario italiano. Psicoter Cogn E Comportamentale [Internet]. 2005 [cited 2019 Dec 18]; 11(1): 7-18. Available from: https://moh-it.pure.elsevier. com/en/publications/type-d-personality-a-relevantconstruct-in-cardiology-preliminary

24. Bergvik S, Sorlie T, Wynn R, Sexton H. Psychometric properties of the Type D scale (DS14) in Norwegian cardiac patients. Scand J Psychol. 2010; 51(4): 334-40.

25. Ferguson E, Williams L, O’Connor RC, Howard S, Hughes BM, Johnston DW, et al. A taxometric analysis of type-D personality. Psychosom Med. 2009; 71(9): 981-6.

26. Alcelik A, Yildirim O, Canan F, Eroglu M, Aktas G, Savli H. A Preliminary Psychometric Evaluation of the Type D Personality Construct in Turkish Hemodialysis Patients. $J$ Mood Disord [Internet]. [cited 2019 Dec 18]; 2(1): 1. Available from: https://www.academia.edu/19551271/ A_Preliminary_Psychometric_Evaluation_of_the_Type_D_ Personality_Construct_in_Turkish_Hemodialysis_Patients

27. Pedersen SS, Yagensky A, Smith ORF, Yagenska O, Shpak V, Denollet J. Preliminary Evidence for the Cross-Cultural Utility of the Type D Personality Construct in the Ukraine. Int J Behav Med [Internet]. 2009 Jun [cited 2019 Dec 18]; 16(2):108-15. Available from: https://www.ncbi. nlm.nih.gov/pmc/articles/PMC2707956/

28. Oginska-Bulik N. Occupational stress and its consequences in healthcare professionals: the role of type D personality. Int J Occup Med Environ Health 2006; 19(2): 113-22.

29. Yu X, Chen Z, Zhang J, Liu X. Coping Mediates the Association Between Type D Personality and Perceived Health in Chinese Patients with Coronary Heart Disease. Int J Behav Med [Internet]. 2011 Sep 1 [cited 2019 Dec 18]; 18(3): 277-84. Available from: https://doi.org/10.1007/ s12529-010-9120-y

30. Yu X, Zhang J, Liu X. Application of the Type D Scale (DS14) in Chinese coronary heart disease patients and healthy controls. J Psychosom Res. 2008; 65(6): 595-601.

31. Kyriazos TA. Applied Psychometrics: Sample Size and Sample Power Considerations in Factor Analysis (EFA, CFA) and SEM in General. Psychology [Internet]. 2018 [cited 2020 Jun 5]; 09(08): 2207-30. Available from: http:/ /www.scirp.org/journal/doi.aspx?DOI=10.4236/psych. 2018.98126

32. Bhatnagar R, Kim J, E. Many J. Candidate Surveys on Program Evaluation: Examining Instrument Reliability, Validity and Program Effectiveness. Am J Educ Res [Internet]. 2014 Aug 7 [cited 2020 Jan 8]; 2(8): 683-90. Available from: http://pubs.sciepub.com/education/2/8/18/ index.html 
33. Cronbach LJ. Coefficient alpha and the internal structure of tests. Psychometrika [Internet]. 1951 Sep 1 [cited 2020 Jan 8]; 16(3): 297-334. Available from: https://doi.org/ 10.1007/BF02310555

34. Bentler PM. Comparative fit indexes in structural models. Psychol Bull. 1990; 107(2): 238-46.

35. Tucker LR, Lewis C. A reliability coefficient for maximum likelihood factor analysis. Psychometrika [Internet]. 1973 Mar 1 [cited 2020 Jun 4]; 38(1): 1-10. Available from: https:/ /doi.org/10.1007/BF02291170

36. Browne MW, Cudeck R. Alternative Ways of Assessing Model Fit: Sociol Methods Res [Internet]. 2016 Jun 29 [cited 2020 Jun 4]; Available from: https://journals. sagepub.com/doi/10.1177/0049124192021002005

37. Cabrera-Nguyen P. Author Guidelines for Reporting Scale Development and Validation Results in the Journal of the Society for Social Work and Research. J Soc Soc Work Res [Internet]. 2010 Jan [cited 2020 Jun 5]; 1(2): 99-103.
Available from: https://www.journals.uchicago.edu/doi/ 10.5243/jsswr.2010.8

38. Worthington RL, Whittaker TA. Scale Development Research: A Content Analysis and Recommendations for Best Practices. Couns Psychol [Internet]. 2006 Nov [cited 2020 Jun 5]; 34(6): 806-38. Available from: http:// journals.sagepub.com/doi/10.1177/0011000006288127

39. Bagherian R, Bahrami Ehsan H. Psychometric Properties of the Persian Version of Type D Personality Scale (DS14). Iran J Psychiatry Behav Sci [Internet]. 2011 [cited 2019 Dec 11]; 5(2): 12-7. Available from: https://www. ncbi.nlm. nih.gov/pmc/articles/PMC3939967/

40. Batsele E, Denollet J, Lussier A, Loas G, Vanden Eynde S, Van de Borne P, et al. Type D personality: Application of DS14 French version in general and clinical populations. $J$ Health Psychol [Internet]. 2017 Jul [cited 2019 Dec 11]; 22(8): 1075-83. Available from: http://journals. sagepub. com/doi/10.1177/1359105315624499 